\title{
China's Online Retail Market in an Era of Technological Innovations
}

\author{
Gal Forer \\ KoGuan Law School, Shanghai Jiao Tong University, Shanghai, China \\ Email: gal.forer@gmail.com
}

How to cite this paper: Forer, G. (2019). China's Online Retail Market in an Era of Technological Innovations. Beijing Law Review, 10, 698-729.

https://doi.org/10.4236/blr.2019.104040

Received: May 22, 2019

Accepted: August 4, 2019

Published: August 7, 2019

Copyright $\odot 2019$ by author(s) and Scientific Research Publishing Inc. This work is licensed under the Creative Commons Attribution International License (CC BY 4.0).

http://creativecommons.org/licenses/by/4.0/

\begin{abstract}
The immense scope of global e-commerce sales, expected to reach USD 4.48 trillion by 2021, is growing much faster than e-commerce and online retail legislation. In China, where the number of online shoppers is expected to reach 798.8 million by 2020 of which almost $42 \%$ use mobile devices for payment, lawmakers have been overhauling internet law, and its efforts reveal innovative methods and criteria deserve closer observation. The article will focus on the analysis of e-commerce from three legal aspects: contracts, consumer protection and unfair competition. This area holds vast practical relevance, especially in a world constantly shifting from traditional transaction and shopping methods towards internet-based technology and online transactions. Hence, the importance of legal recourse that is able to rapidly adapt to the technological developments introduced by e-commerce. The article's findings indicate that specific regulation of e-commerce activities is vital in the virtual world, where conventional concepts of law and the laws themselves can be difficult to apply. From the analysis of the new PRC E-Commerce Law, it appears to be well-balanced in its goals by providing improved protection to all online trading parties and ensuring the safe development of China's online economy. However, it still raises some questions that require of further debate and lobbying, as will be presented in the article itself.
\end{abstract}

\section{Keywords}

PRC E-Commerce Law, Contracts, Consumer Protection and Privacy, Unfair Competition, Internet Law

\section{Introduction}

Ever since I met Jack Ma (founder and chairman of Alibaba Group), I have had two great successes. successful login and successful payment, and owned a ve- 
hicle of my own: a shopping cart. I also got to know my biggest weakness: lack of money in my bank account. ${ }^{1}$

-Viral Internet joke (author unknown)

“We need banking but we don't need banks anymore" (TechPapa, 2017), said Bill Gates 20 years ago, predicting the future explosion in startup companies creating web and application-based financial services. Today, few will disagree that Mr. Gate's vision has become a reality. For instance, it is commonplace to see customers in a Shanghai Starbucks using a mobile wallet application to pay for coffee by simply waving their phone in front of a barcode scanner. Traditional methods of financial transactions and platforms, such as face-to-face cash and credit card transactions gradually decline. Proof of this can be seen by disappearing queues in cash-less banks and traditional stores being coined "brick and mortar" shops to imply they are becoming a thing of the past.

This emerging shift of trade from traditional sales in shops and shopping centers to online transactions is constantly growing worldwide. In 2017, retail e-commerce sales worldwide reached USD 2.3 trillion and e-retail revenue was projected to grow to USD 4.48 trillion in 2021 (Statista, 2017). The growth of online retail is especially evident in Asia, where nearly USD 1.35 trillion were invested in 2017 (Orendorff, 2018). In China, retail e-commerce sales in 2018 were almost USD 600 billion, carried out by over 650 million Chinese online shoppers, a number expected to reach almost 800 million by 2020 (Eshopworld, 2019). To emphasize this point, on November 11, 2018 (China's Singles Day), Alibaba Group (Chinese conglomerate of Internet-based businesses) processed over USD 30.8 billion in sales in just 24 hours, compared to USD 25.3 billion in 2017 (an increase of 27\%). By achieving these numbers, China's Singles Day surpassed the United States' Black Friday as the world's most lucrative online shopping festival (Kharpal, 2018), (That's Shanghai, 2017), (Luo, 2016).

China is also one of the leading FinTech countries, both for the number of total users and market size. In 2016, a record of 195 million Chinese shoppers used FinTech platforms for in-store and online payments (TechPapa, 2017). According to expert predictions, these numbers will continue to rise and reach an estimated 332 million shoppers in 2020 (TechPapa, 2017).

Electronic commerce (hereinafter: "e-commerce") has been defined as "commerce conducted via the Internet" (Miriam Webster Unabridged Online Dictionary, 2017) and this article will analyze the emerging legal implications of this growing phenomenon, and more specifically online retail, in China. Unfortunately, the term "online retail" does not yet have a dictionary definition, but the term itself is self-defining. This is the emerging distinction between e-commerce, as a term that envelops all internet transactions (including services), and "online retail" which is more product and merchandise oriented. It is also unfortunate that this distinction has not reached legislative bodies in China, so current legislation only refers to e-commerce.

In Chinese; “自从认识马云之后, 我获得了两大成功: 登录成功, 付款成功, 还拥有了属于 自己的一辆车: 购物车。我也明白了自己最大的不足: 余额不足! ” 
E-commerce and online retail involve many branches of civil and commercial law, however, this article will focus on the analysis of e-commerce from three legal aspects: contracts, consumer protection and unfair competition. The article will also attempt to analyze the legal characteristics of online transactions compared to face-to-face sales, and deal with the effect of e-commerce on the traditional Chinese legal system and assess whether the new e-commerce law can fully cope with the ever-changing Chinese e-commerce market. Finally, recommendations will be offered for the clarification of various aspects of the E-Commerce Law that need to be addressed in light of China's online revolution.

Since the digital market has different characteristics from ordinary trade in the classic market, its unique regulation is necessary to better protect online trading partners (e.g., e-commerce platforms, business operators and consumers), and to ensure safe online domestic and cross-border trade. Some may argue that e-commerce has completely disrupted the nature and scope of relationships between trading partners, which has resulted in the market coming close to meeting "perfect market conditions".

However, one cannot ignore the neo-classical microeconomic model of Adam Smith (Laissez Faire), (Smith, 1776) which states that the market forces are sufficient to create the dynamics necessary for achieving the goals of aggregating social welfare, reducing superiority gaps between the trading partners, and ensuring the consumer's ability to make wise decisions, does not suffice in the world of e-commerce and online retail. Hence, Chinese lawmakers did well in addressing the digital market through specific legislation (Jabareen, 2015).

Research and analysis of China's booming e-commerce and online retail market is especially interesting since China is currently the second largest economy after the United States, but leads from the perspective of the number of online transactions (both domestic and cross-border), e-commerce platforms (e.g., Alibaba Group's subsidiaries Taobao, Tmall, AliExpress etc.), mobile payment applications (e.g., Alibaba's Alipay, Tencent's WeChat Pay etc.) and in terms of the market's rapid regulation, as will be presented in the article itself.

\section{E-Commerce and Online Retail}

\subsection{Definition of E-Commerce}

There is an emerging distinction between e-commerce and "online retail" which is not always clear, and as current legislature in all forms (e.g., laws, drafts), relates only to e-commerce in the general sense of the term, it is assumed these laws will also apply to online retail in particular. E-commerce ${ }^{2}$ is defined diffe${ }^{2}$ For general literature on e-commerce, please see Kenneth C. Laudon \& Carol Guercio Traver, E-Commerce: Business, Technology, Society (2002); Kenneth Kraemer, Global E-Commerce: Impacts of National Environment and Policy (2011); Paul May, The Business of E-Commerce: From Corporate Strategy to Technology (2000); Keith Brown, The Interactive Marketplace (2000); Catherine L. Mann, and others, Global Electronic Commerce: A Policy Primer (2000); Faisal Hoque, David Orchard E-Enterprise: Business Models, Architecture, and Components (2000). 
rently in various sources. However, these definitions have a broad common ground. Here are the main definitions of e-commerce:

- "... the conduct of commercial activities through electronic means" (Li, 2003).

- "The delivery of information, products (tangible and intangible), services, or payments by telephone, computer, or other automated media" (Canadian Advisory Committee on Electronic Commerce $\$ 1.2,1998$ ).

"The first component in this definition of e-commerce requires an economic transaction. A "transaction" is a process consisting of several stages: it starts with negotiations, continues with the signing of the contract related to the transaction as a "sale or service contract", payment is carried out, and then the contract, including all its stipulations, must be fulfilled. The second component of this definition is what distinguishes e-commerce from conventional methods of trade; e-commerce is executed by using the Internet. The third component clarifies what part of a transaction is made by using the Internet. the transaction in whole or only in part, since it is possible that not all stages of a transaction will be carried out by using the Internet as a platform. It should be noted that this stage is significant for the transaction's conclusion and performance. It appears that the preliminary stage of negotiations is not substantial, and the contract's conclusion symbolizes the commencement of the most substantial stage, which introduces the transaction into the scope of e-commerce.

In addition, it is important to differentiate between three main types of e-commerce transactions, specific for the item being traded:

1) E-commerce in tangible products (e.g., electronics, books, clothing and footwear, jewelry etc.). A consumer connects to the Internet network and enters an e-commerce website such as eBay, Amazon or Taobao, orders a book and pays with credit card or electronic money (PayPal or Alipay), and the e-commerce platform receives the payment for the product itself. The book will be sent from the platform's retailers to the consumer's residence within a few days via logistic companies. At the center of this transaction there is a tangible product (a book). This product physically exists and sent from the platform's retailers to the consumer. The electronic components in this transaction are the order of the product and payment.

2) E-commerce in intangible products (e.g., e-commerce in digital content (information products); information that exists in different forms, such as text, photos, videos etc.). An online transaction, in which the firm gives the consumer rights over digital content. Digital content transactions are quite diversified, and include a wide range of transactions. For example, content (news, games, movies, software, etc.), source of content (content originating from a website's system, or third parties who own it, or users' content), the content's legal status (protected by intellectual property or not), the nature of the rights granted in relation to the content, the manner in which the content is transferred, and more. To emphasize this type of transaction, let's assume that a certain company develops software at its software development centers in country $\mathrm{X}$ andcountry $\mathrm{Y}$ 
and other places in the world. Consumers enter the company's website, order the software, pay with credit card or electronic money to firms for the right to use the digital content, and then download the software to their personal computer. In this transaction, the product's order, payment and delivery are executed via the Internet. Another business model that firms operate in the digital content market is the "advertising modep". According to this model, the firm gives consumers the rights to use digital content for free, thereby increasing the number of consumers who visit its website and thus, increasing the customer base and making the sale of advertising space more attractive.

3) E-commerce in services. Many firms provide consumers with various services over the Internet. Some of these services are familiar to us from the classic market, such as tourism, consulting, brokering, and dating services. For example, let us assume there is a specialist working for Microsoft software (in country $\mathrm{X}$ ) who runs a website named MiscrosoftHelp.com. Different customers worldwide connect to the website. For a one-time fee or annual subscription, they connect to an online video call with country X's professionals and they reply to each of their questions regarding the software usage. The core of this type of transaction is the support services provided by country X's experts for any questions customers from around the world may have concerning the operation of the software. There are many other online services that belong to this category, such as the service provided by social networks, which grant consumers with services that were not previously known in classic markets (e.g., contacting others based on friendship, professional or any other common interest via Facebook, Twitter, LinkedIn, etc.). These websites belong to another advertising model, which gives users an online service for free and as a result, enlarge the number of consumers who visit in their website, enabling these service providers to sell advertisement spaces to a larger customer base.

The basis of all types of online transactions is similar in essence, since the Internet is the medium being used to carry them out. The difference between the various transaction types lies in the extent of the Internet's usage, and how it is involved in the transaction. In most cases, e-commerce in tangible products is used for the product's order and payment, but the manufacturing of the physical product and its delivery are done in the non-digital world. Nevertheless, when it comes to e-commerce in intangible products, the product's delivery, or supply of services, are normally completed over the Internet. In contrast to tangible products, when trading in intangible products and services, the product's delivery or provision of services are usually processed over the Internet without any "physical entity", and the extent to which the Internet is used in these types of transactions is therefore, generally greater than that of the first type (e-commerce in physical products) (Azam, 2013), (Jabareen, 2015).

\subsection{E-Commerce in Practice}

E-commerce is based on the Internet's network infrastructure (interconnected networks). The Internet is basically a network of computers or computer net- 
works, which are connected by cables or other connection methods (Girasa, 2002). Every computer connected to the network has a number (IP Address). However, there is no link between this number and the person using the computer or its location. This is the basic physical infrastructure of the Internet.

The World Wide Web (WWW) is the tool giving life and meaning to computers, which are connected to the Internet network by providing access and flow of information between different computers using a communication code, which is called "Transmission Control Protocol”/“Internet Protocol” (TCP/IP) (Girasa, 2002), (Azam, 2013). The data are found in "storage tools" (hard disks) of the different computers which are connected to the network. The data are transmitted from one computer to another by routers and switches. These computers are designed to transmit data in the fastest way at the relevant time from the source computer to the destination computer. The data pass randomly through different pathways that were found to be optimal at the time of transmission.

This system can be compared to a virtual globe, which is similar to a certain extent to the physical globe: every computer in the world is a point around the globe, which has an identification number (IP). Though, the computer's number does not connect the computer itself to a physical location in the physical globe, rather the computer's number can be linked to a location. Each computer has data (the computer's content) which is similar to the content of each point around the globe. These computers are connected through cables and other means of connection, which are the routes and roads that can be found in the physical globe. The WWW is the map illustrating all the different points in the virtual globe and the routes between them.

These characteristics of e-commerce and online retail, which in practice bridges borders and geographical distances, can have significant implications concerning contracts, consumer protection and privacy, and unfair competition. These traits are the core challenges that e-commerce poses to these legal issues, especially in complex transactions where lawmakers have yet to define binding regulations.

The Internet's main characteristics are (Azam, 2013):

- Globalization: this feature is related to global trade that knows no territorial boundaries. E-commerce is conducted on a virtual globe, which covers the physical globe. Trade is not limited to a specific location, making tangible physical international borders almost meaningless which is the most prominent feature of the Internet in general, and e-commerce in particular.

- Virtual Trading: virtual trading has no real tangible ties to the physical world. Trade is not carried out in a specific location, but everywhere and all the time. The Internet is the only place in the physical world where e-commerce is carried out. Indeed, certain parts of the trade process do have physical locations, such as the transfer of a tangible product in one physical location to another, but e-commerce as a method of trade, and as a unit as a whole, is only possible in the virtual global marketplace and any attempt to anchor it 
in one specific physical location is destined to fail.

- Anonymity: according to the existing structure of the Internet and e-commerce, the very existence of trade and its parties are anonymous. As previously stated, there is no link between the computer and a specific person or location, and therefore, parties to the transaction remain unidentified.

- Non-Centralization: the Internet's structure is not centralized, and no one country or entity controls it. However, this does not mean that the Internet is freely available, as there are countries that block or censor internet content and services that have been deemed inappropriate by the government (e.g., China's Internet filtering policy).

- Development and Accelerated Progress: the technology underlying e commerce develops and advances at an accelerated pace, as does the scope of e-commerce.

\subsection{Online vs. Offline Retail (Shackleton, 2016)}

" $A$ market", in its economic sense, is defined as a collection of sellers and buyers, dealing with the exchange of a given product or service, subject to a specified set of rules, procedures and customs (Jabareen, 2015). Consumer activity does not occur in an empty space; the mechanism in which this activity takes place is commonly called "the market". The market is the space in which goods and services are marketed and traded. The mechanism in which consumer activity is carried out outside the Internet is called the "classic market", while the mechanism used by consumers on the Internet is called the "digital market" (Jabareen, 2015).

A common argument in economics is that each market has a unique structure that distinguishes it from the other markets. For example, different market players, traded goods, marketing methods and trading processes, and the infrastructure and rules supporting the existence of trade. Therefore, the question that arises in this context is whether there is a fundamental difference between classic and digital markets that justifies separate regulation, or are there only minor differences, to the extent that they can be viewed as identical markets? If there is a difference, what is its nature, essence and scope? (Jabareen, 2015)

These questions and their answers are the basis for normative regulation of consumer e-commerce and online retail. This article will attempt to answer these questions, especially the main question of adapting existing laws that are widely accepted in the classic market and projecting them to the regulation of trade in the digital market. The assumption in this article is that as the differences between the classic and digital markets deepen, the ability of existing laws to adequately address consumer e-commerce and online retail diminishes, which means that the adoption of specific laws for these online retail activities is required (Jabareen, 2015).

Both classic and digital markets deal with trading for products and services, but there are major differences between selling goods online through a store on Taobao, Tmall or eBay, and selling in a traditional "brick and mortar" store. 
When the average consumer visits a mall and carries out a transaction, it is generally face-to-face between the consumer and the firm (or someone on its behalf). In this type of transaction, almost no other parties are involved, except from the buyers and sellers themselves (excluding cases where the payment is made by credit card, which involves the credit company). In the digital market, nevertheless, consumers encounter many intermediating factors ("intermediators") during the various stages of the online transaction which provide different services ${ }^{3}$ related to the transaction itself, depending on the firm's business model (Jabareen, 2015). The personal interaction with consumers has become almost non-existent in online transactions, while the hiring of congenial sales staff is key to traditional businesses.

Although global online retail continues to grow at an exceptional rate (in 2018, global e-retail sales grew 23.3\% compared to 2017) (Statista, Annual Retail E-Commerce Sales Growth Worldwide from 2014 to 2021, n.d.) and many pundits have forecasted the eventual demise of the traditional shopping mall, most people still actually prefer to shop in-store, so "brick and mortar" stores are far from becoming obsolete (Shackleton, 2016).

\subsubsection{Online Retail}

Online retail, or electronic commerce, mainly refers to consumer activity taking place over the Internet, which can be referred as "consumer electronic activity", "consumer e-commerce" or "business to consumer e-commerce" (B2C), as opposed to e-commerce between two business entities (B2B) or between two consumers (C2C). This article will mainly deal with the first type: B2C e-commerce.

According to this definition, e-commerce includes a series of commercial-consumer activities carried out on the Internet, such as marketing, searching for products and services, selling, purchasing, entering into a sale or service contract, providing a product or service, etc. The main difference between consumer online and offline retail is the way in which trade is conducted: online retail takes place on the Internet, while the regular trade occurs outside the Internet (in this sense, even commerce which is conducted via smartphones over the Internet (Mobile Commerce), is considered as a type of consumer e-commerce) (Jabareen, 2015).

It should be mentioned that the general essence of consumer transactions is for personal, domestic or family purposes. Thus, a consumer e-commerce transaction is a transaction conducted on the Internet for personal, domestic or for family purposes (Jabareen, 2015).

Additionally, setting up an online store comes with significantly lower startup costs than a traditional physical store. There is no need to pay for a large physical space in a prime location, merchandise does not need to be arranged on shelves in air-conditioned showrooms, and in some cases inventory is not re-

${ }^{3}$ For example, services of Internet access providers, consumer search engines that act as information intermediators, and virtual malls that serve as a platform for connecting between sellers and consumers, intermediators who provide online dispute resolution (ODR) services and online payment services, etc. 
quired at all. This results in lower fixed costs, requires less capital investment and usually allows the business owner to begin selling in a shorter period of time.

Convenience is the key feature of online retail. Many consumers enjoy shopping from home at a time that suits them, and without having to face aggressive sales representatives working on commission. These online shoppers do not receive instant satisfaction from their purchases, but having products delivered straight to their door within a few days, often outweighs other considerations. From an online retailer's point of view, in addition to the physical advantages of a virtual store, being able to accurately track the customer's inquiries and transactions across multiple platforms, provides data for marketing efforts beyond anything a traditional store could ever generate.

Online stores are not necessarily immediate success stories, even though they can be simpler and less costly to set up than physical establishments. As opposed to a traditional store, where consumers can be lured into the depths of the store while having to pass other strategically located merchandise, it is costlier to ensure that they "stroll" through a virtual store. Sellers must accept that a larger marketing budget is required, compared to a traditional store. They also need to allocate more resources and time to marketing and advertising to let potential customers know they exist and are open for business.

Traditional brick and mortar stores also have the advantage of "the personnel touch", whereas online stores find it more difficult to build meaningful interactions with customers. Online businesses need to work hard to bridge the lack of face-to-face interaction and make sure that consumers have confidence in their store and brand.

\subsubsection{Offline Retail}

Offline retail remains the most popular shopping channel for consumers and cannot yet be matched by virtual shopping, when it comes to customer experience (Shackleton, 2016). With a traditional store, sellers can create a unique experience for their customers and express their brand in a creative way.

Having a traditional store also enables sellers an instant access to passing pedestrian trade, without having to invest in marketing. Having a great store location can make sellers easily visible to their target market and can build their brand locally. However, offline retail has several disadvantages when compared to online retail. For example, higher set-up and operating costs, more employees are required, and hours of operation are often limited. This allows less room for error, when it comes to the initial financial investment. With an offline store, cash flows can quickly disappear if the business model has not been carefully considered.

There is currently a trend of not just traditional retailers opening online stores, but also online retailers investing in physical locations (Shackleton, 2016), so the boundaries between the two types of retailers are becoming increasingly blurred. Even for an online retailer, having a physical store is an impressive way 
to express a vision for a brand, sell customer experience and reach new markets.

It seems like the future of sales involves an interaction between sellers and buyers via different platforms, both physical and digital, as in-store technology and as e-commerce platforms shall facilitate the connection of customers to online and offline stores.

\subsection{E-Commerce in China}

China's economy has been growing steadily for over two decades, however its booming e-commerce market (online retail platforms, online payment services and mobile wallets, and myriad smartphone applications), require analysis from both empirical and legal perspectives. Support for the dramatic growth of China's e-commerce market in recent years, and its rapid progress towards becoming a "cashless society", due to the widespread use of mobile payment applications, can be found in a recent survey. Conducted by Tencent (a Chinese tech giant), in collaboration with the Chongyang Institute for Financial Studies at Renmin University and Ipsos (the French market research firm), the survey attempted to measure this new phenomenon by asking residents of 324 different Chinese cities how comfortable they were with using mobile payment applications (China Daily, 2017).

Just over half of the respondents said that they only used cash in merely $20 \%$ of their daily purchases; and about 40\% said they carried less than RMB 100 in cash when they shopped in local stores. More than $70 \%$ said they could get on comfortably for more than a week with only RMB 100 in cash while $84 \%$ said that they were comfortable going out of their homes without any cash in pocket, as long as they were carrying a mobile phone (Ipsos, 2017). According to a report issued by Goldman Sachs, Chinese e-commerce sales reached USD 750 billion in 2016, stemming from 460 million online shoppers, and predicts a CAGR of $23 \%$ in 2020 almost triple that of offline sales. Goldman Sachs has also estimated China's e-commerce market will reach USD 1.7 trillion in 2020 (O'Brien, 2017).

The main factors behind this steep increase are the rise of China's standard of living and disposable income as a result of more attractive online prices and a wider selection of available products compared to traditional stores. Other factors contributing to the increase in online retail sales include payment by credit cards and the development of third-party payment services, such as Alipay or WeChat Pay (Israeli Chamber of Commerce in Beijing, 2016). Unlike other markets, China's online retail market is dominated by sales through trade platforms and not through independent websites. The two leading e-commerce platforms accounted for nearly $80 \%$ of China's total online retail sales in 2014 (Tmall 59\%, JD.com 20\%) and were expected to claim an even higher market share by 2015 (Israeli Chamber of Commerce in Beijing, 2016).

The main platforms in the "others" category in China's online retail market are YiHaoDian, Amazon, Gome, VIP and Jumei, but all of them together only account for $10 \%$ of the online market's share. All the rest are smaller specialized platforms and independent sales websites of different companies (Israeli Cham- 
ber of Commerce in Beijing, 2016). About half of the online sales in China in 2014 were made by customers in more developed coastal areas, such as Guangdong, Shanghai and Zhejiang provinces. However, the demand in China's inner provinces has increased significantly in recent years, especially in areas where retail chains of large brands do not exist or whose presence is low (Israeli Chamber of Commerce in Beijing, 2016). These findings were validated by data published after China's 2018 Singles Day.

Regarding market share, Tmall holds $68 \%$, while the second largest stakeholder, JD.com, claims up $17.3 \%$ market share. Guangdong, Zhejiang and Jiangsu ranked as the top three provinces in terms of transaction volume (Graziani, 2018). Data shows that there had been a steady increase in the number of Internet users in China, According to the $42^{\text {nd }}$ bi-annual statistical report from the China Internet Network information Center (CNNIC), the number of internet users in China reached 802 million at the end of June 2018 (57.7 percent of the country's population), a rise of 3.8 percent from February 2018. Almost 71 percent of these users were online shoppers nearly 569 million people (Liang, 2018), (Li Xia, 2018).

The scope of e-commerce has also expanded: Tencent Holdings Ltd., which holds WeChat Pay, and Alibaba Group Holding Ltd.'s affiliate Alipay, recently announced their intentions to globally expand their payment services to enable users to make payments by using a convenient code scan (Tencent Holdings Plans to Expand WeChat Pay Beyond China, 2017). Another reason for the prosperity of e-commerce platforms in China is the fast development of China's economy and the GDP's growth. According to China's National Bureau of Statistics, China's GDP expanded in 6.6\% year-on-year in 2018, exceeding RMB 90 billion (National Bureau of Statistics of China, 2019).

The assumption is that the expansion of the Chinese online retail market will continue to grow as public trust increases due to more robust internet security. Most e-commerce transactions are currently completed between businesses (B2B), but online trading is also rapidly developing between businesses and consumers (B2C), and it is highly likely that this field will continue to command a significant share of China's online economy (Azam, 2013).

\subsection{E-Commerce and Online Retail-Summary of Definitions}

The emerging definitions of e-commerce are becoming clearer and better accepted as those currently published hardly differ from those that preceded them. It is generally agreed that this type of commerce addresses three main areas of transactions: tangible products, intangible products and services, all of which are carried out and completed over the Internet using physical hardware (e.g., computers, routers, servers, etc.) and international protocols to manage myriad amounts of data. The Internet's trading arena has many characteristics, such as globalization, virtual trading, party anonymity, non-centralization and accelerated progress and development.

Due to these characteristics that are unique to the Internet, the comparison of 
online and offline retail must be addressed from the perspective of the various stages of the transaction process. Transaction terminology, such as "marketing", "sales representatives" and "advertising" take on different meanings in conventional and Internet domains, and conventional laws are not necessarily suitable for both.

The aforementioned characteristics and terminology are becoming ubiquitousin China as the scope of e-commerce booms. This rapid growth is a driving force for change in Chinese legislature as this detailed further in this article.

\section{PRC E-Commerce Law (2018)}

After a lengthy deliberation process, the fifth meeting of the Standing Committee for the 13th National People's Congress of China (the "NPC"), approved the much awaited and needed E-Commerce Law (E-Commerce Law of the People's Republic of China, 2018) (the "ECL"), on August 31, 2018. The new law, which came into effect on January 1, 2019 (ECL, Art. 89), is the result of the two official drafts that were released by the NPC for public comments on December 27, 2016 and on November 7, 2017 pursuant to the standard national law-making process (HFG Law \& Intellectual Property, 2017), (Zhong Lin and Galaad Delval, 2018).

Based on the ECL's structure and drafts, it seems that the Chinese legislator was aware of the need for separate and specific regulation of China's e-commerce market. Accordingly, the ECL strives to promote the sustainable and healthy development of e-commerce, regulate e-commerce conduct, and ensure the lawful rights and interests of entities engaged in e-commerce business activities (ECL, Art. 1).

In addition, the Chinese government encourages business activities that develop new forms of e-commerce, innovate business models, promote the application of new technologies in e-commerce and create a favorable market environment for innovation (ECL, Art. 3). Parties to e-commerce activities are expected to abide by the principlesof voluntariness, impartiality, honesty and good faith, and adhere to accepted commercial morals in their business transactions. This means they are required to fulfill their obligations in areas such as the protection of consumer rights, the environment, intellectual property rights, network security and personal information, in addition to being responsible for the quality of their products and services while accepting government and public oversight (ECL, Art. 5).

The term "e-commerce" is broadly defined under the ECL and refers to business activities of selling goods or providing services through information networks, such as the Internet. The ECL does not apply to financial products and services, news information, audio or video programs, or publication and cultural services (ECL, Art. 2). The ECL adopted the narrow approach presented in its second draft, which only applies within Mainland China and does not address cross-border e-commerce, where domestic business operators or consumers par- 
ticipate (Zhong \& Galaad, 2018). It is worth noting that the ECL is only supplementary to the existing PRC laws and regulations for the sale of goods or provision of services, and these specific provisions shall prevail (ECL, Art. 2).

In addition, the ECL provides three important definitions of the main players in China's e-commerce market that fall under its jurisdiction (ECL, Art. 9):

1) E-commerce platform operators: Any legal persons or organizations providing cyberspace, virtual business premises, transaction matching, information distribution and other services to two or more parties to an e-commerce transaction so that the parties may engage in independent transactions (e.g., Taobao owned by Alibaba);

2) On-platform business operators: e-commerce operators that sell goods or provide services to customers through e-commerce platforms (e.g., a seller operating an online store on Taobao).

3) Online sellers. other e-commerce players doing business through self established websites or through other online channels, such as social media applications (e.g., sales on WeChat or live streaming applications).

\subsection{Contractual Relationships}

Third-party e-commerce platforms are required to draft their service agreements and trade policies in compliance with principles of openness, fairness and impartiality to regulate their relationship with online-product business operators and consumers, which must include provisions concerning the entry-exit of the platform, the guarantee of the quality of goods and services, and address the protection of consumer rights and interests, personal information protection and other areas. These contracts shall be continuously and clearly displayed and available on the platform's website and filed with authorities (ECL, Art. 32-33).

Any amendment of the platform's trading rules shall be made in compliance with the principles of openness and reasonableness and be publicized at least 7 days before their effective date. Any stakeholder may be able to make comments and a way out shall be given to business operators who disagree with these modifications, subject to a suitable assumption of liabilities under the previous trading rules (ECL, Art. 34).

Similarly, to its second draft, The ECL refers to the use of standard contracts and provides contractual protection for e-commerce business operators registered with third-party e-commerce platforms. E-commerce platforms shall not exploit service agreements, transaction rules or technical methods to unreasonably restrict or place unreasonable requirements for transactions with business operators (ECL, Art. 35).

\subsubsection{Conclusion and Fulfillment of E-Commerce Contracts}

The ECL applies to contracts concluded between e-commerce parties and further stipulates that matters not covered by its provisions be regulated by the PRC General Provisions of the Civil Law, PRC Contract Law and Electronic Signature Law (ECL, Art. 47). 
In addition, the ECL recognizes the use of automatic information systems to form or perform contractual action as legally effective. Parties to an e-contract are presumed to possess the appropriate capacity for civil conduct and express their genuine intent, unless there is contradicting evidence (ECL, Art. 48). The e-contract shall be seen as validly entered when information on goods and services released by an e-commerce business operator complies with the terms of an offer and the consumer submits the order, unless the parties agree otherwise (ECL, Art. 49(1)).

The determination of the arrival time of an electronic offer or acceptance shall be in accordance with Article 16 of the PRC Contract Law (Contract Law of the People's Republic of China, 1999), i.e., the time when the electronic message enters the designated special system; and in the absence of such system, the time when the electronic message first enters into any of the recipient's systems.

E-commerce business operators, pursuant to the principles of openness, fairness and impartiality, must clearly, comprehensively, and explicitly inform their users of the steps that form a contract, matters needing attention, downloading methods, and other such matters (ECL, Art. 50(1)).

In addition, e-commerce business operators are not allowed to include in the standard user terms of the e-commerce platform, provisions allowing them to cancel their contract with consumers after payment has been accepted. If such content appears in the standard terms, it shall be deemed invalid (ECL, Art. 49(2)). The ECL recognizes the performance of e-contracts with an automatic transaction information system, even if the user wrongly submits an order into such system. Therefore, business operators shall ensure that users can correct input errors before submitting an order (ECL, Art. 50(2)).

Where e-commerce business operators selling goods or providing services do not perform their contractual obligations under law or contracts they are party to, or cause harm to others, they shall bear a civil liability in accordance with law (ECL, Art. 74).

\subsubsection{Electronic Payment}

Chinese legislation addressed the requirements concerning "payment through the network", and defined it as "transfer of monetary funds between payers and payees via public or private networks" in various ways (e.g., cell phones, money transfers, etc.) (Administrative Measures for the Payment Services Provided by Non-Financial Institutions, Art. 2 (4), 2010). This includes the following rights and obligations:

- Payment institutions: The People's Bank of China and the State Council's bank administration authority shall conduct supervision and regulation of electronic payment service providers (Measures on the Administration of Online Transactions, Art. 5, 2014);

- Electronic payment service providers. An electronic payment service provider shall provide secured payment services. It shall conduct real-name account management for electronic payment service recipients and notify them for 
the functions, methods and risks related to e-payment services (ECL, Art. $53)$;

- Electronic payment recipients. An electronic payment recipient must provide electronic payment service providers accurate and valid identity and contact information, and avoid wrongful and unauthorized payments (ECL, Art. 55).

Upon completion of the electronic payment, the electronic payment service provider shall promptly and accurately provide payment confirmation to the recipient (ECL, Art. 56). In the event that an electronic payment service provider violates any related statutory requirements for financial information security management, it is liable for compensation for related losses incurred to users (ECL, Art. 54). For damages caused by unauthorized payments, the online-payment service provider will automatically be held liable if immediate measures to prevent further losses were not taken, unless it can prove that such losses were caused by the recipient of the online payment service (ECL, Art. 55). In contrast, the electronic payment service recipient shall be responsible for the accuracy of unauthorized payment orders it has issued (ECL, Art. 57).

\subsubsection{Logistics}

Where the subject matter of an e-contract is goods that will be delivered by a courier service, the time of delivery shall be the time of receipt by the logistic service recipient. Where the e-contract's subject matter is a service, the time of delivery shall be the time when an electronic receipt is produced or as stated on a paper-based receipt. Where the subject matter is a digital product provided online, the delivery time shall be that when the digital product is sent by the party fulfilling delivery obligation to a specific system designated by the other party and can be retrieved and identified. These provisions are valid, unless the parties have otherwise agreed on method or time of delivery (ECL, Art. 51).

The ECL addresses the issue of risks and liabilities assumed during transportation, in case of delay in delivery, damage or loss. E-commerce operators shall deliver goods or services to consumers in the manner and time provided in commitments or as agreed upon with consumers, and assume the risks and liabilities for transport of goods, unless consumers reach an agreement with e-commerce operators to select a courier or another logistics service provider (ECL, Art. 20).

\subsection{Protection of Personal Information and Privacy}

Although the ECL's first draft listed some obligations for e-commerce operators in relation to the security of e-commerce transactions and protection of users' personal information (Draft E-Commerce Law of the People's Republic of China, Chapter 4, Section 1, 2016), the ECL adopted the second draft's approach (Eugene Low et al., 2017), (New China Data Privacy Standard Looks More Far-Reaching than GDPR, 2018) and replaced such provisions with a simple reference to the PRC Cybersecurity Law (Cybersecurity Law of the People's Republic of China, 2016): 
When collecting and using users' personal data, e-commerce business operators must abide by existing Chinese laws and regulations concerning the protection of personal information (ECL, Art. 23). The ECL further requires e-commerce business operators to clearly specify procedures for customer inquiries concerning the correction and deletion of user information, and for the cancellation of user accounts. When an e-commerce business operator receives such a request, it must respond in a timely manner upon verifying the requester's identity. When a user cancels their account, the e-commerce business operator must immediately delete relevant user information, unless otherwise provided by laws or regulations or agreed upon by the parties (ECL, Art. 24).

In case of leakage, loss or damage of personal information, the e-commerce business operator must immediately take remedial measures, promptly notify the users and submit a report to the relevant authorities (ECL, Art. 25). Network product and service providers that collect user information are required to obtain consent from users, and they can only use this data in a legal and proper manner in accordance with the law, administrative regulations and their agreements with users. If a network operator has violated the PRC Cybersecurity Law's provisions, individuals have the right to request the e-commerce platform operator delete their personal information that has been illegally collected (Cybersecurity Law of the People's Republic of China, Art. 22, 41-44, 2016). Violators of users' personal information rights and obligationsbe ordered to make corrections, and be subject to confiscation of unlawful gains, and/or be fined between 1 to 10 times these unlawful gains. If unlawful gains are not involved, the fine could reach up to RMB $1,000,000$. Under extreme circumstances, the violating e-commerce platform operators could also be subject to having their business closed until they have rectified their violation, their business license could be revoked, or websites may be closed down all together. Penalties are similar when personal information has been illegally obtained and/or distributed (Cybersecurity Law of the People's Republic of China, 2016).

Compared to its first draft, the ECL addresses cyber-security and greatly expands relevant liabilities and sanctions for the protection of user data in e-commerce activities. The ECL also introduces an EU-style right for users to access, correct or delete any of their personal information saved by e-commerce operators, or to deregister altogether. The Chinese standard extends to any personal data that would cause harm to persons, property reputation, and mental or physical health, if lost or abused. Whilst the European standard reflected in the European Regulation on the Protection of Privacy (the "GDPR"), applies to specific types of data, such as "sensitive personal information". The GDPR is more permissive about certain types of consent requirements for the collection of personal information. It does not strictly require consent to share data, and it allows for legitimate interests of a controller or a third party, which is not found under the Chinese standard (Eugene Low et al., 2017), (New China Data Privacy Standard Looks More Far-Reaching than GDPR, 2018).

E-commerce platforms shall record and store information of goods and ser- 
vices shared on their platform, transaction information, and ensure that the information is complete, confidential, and usable. The storage period for information on goods and services and for transaction information is at least three years from the date on which the transaction was completed; unless other laws and administrative regulations provide otherwise (ECL, Art. 31). Violators shall be ordered by the relevant administration departments to make corrections within a time limit and may be fined between RMB 20,000 and RMB 100,000. Under extreme circumstances, operations may be suspended for rectification and a concurrent fine of between RMB 100,000 and RMB 500,000 may also be issued (ECL, Art. 80(4)).

E-commerce platforms shall adopt technical or other necessary measures to ensure network security and stable operations, and to adopt emergency response plans for network security incidents. When a network security incident occurs, e-commerce platforms shall immediately initiate their emergency response plan, adopt corresponding remedial measures, and report to the relevant regulatory departments (ECL, Art. 30). Users should be informed of the procedure for closing their accounts and e-commerce business operators would be prohibited from circumventing these requirements through unreasonable contractual conditions (ECL, Art. 24).

If e-commerce business operators violate provisions of laws or administrative regulations for the protection of personal information, or do not perform obligations to ensure network security as provided for in article 30 of the ECL and relevant laws and administrative regulations, punishment is to be given in accordance with the PRC Cybersecurity Law and other laws and administrative regulations (ECL, Art. 78 (2)).

\subsection{Consumer Protection}

The ECL proposes to strengthen consumer protection in e-commerce and states that e-commerce operators shall fully, truly, accurately and timely disclose relevant information of the goods and services they offer to protect consumer rights and interests. It reiterates some of the prohibitions under the PRC Advertising Law against the false or misleading advertising, but tailors them to an online setting, i.e., it is forbidden to fabricate false transaction information, write and post fake user reviews or delete genuine user reviews on products and services offered on e-commerce platforms (ECL, Art. 17).This provision not only bans online businesses to use "little treats" to attract positive ratings, but also the use of "click farming" which makes their store seem more popular.

It further requires that e-commerce operators display search results according to indicators such as sales volumes, prices and credit ratings of products or services and defines marketing requirements by obliging paid or sponsored listings to be marked clearly as such (ECL, Art. 18). E-commerce operators bundling products or services shall alert consumers, in an obvious manner, to pay attention, and they must not be the default option or choice when purchasing the item (ECL, Art. 19). This provision aims to protect consumers' rights and inter- 
ests from package deals that are automatically sent without consumers being aware they are spending more money. For instance, a traveler books a flight on a website and is then invited to book a hotel on a different website.

Violators of the above provisions shall be ordered by the market supervision and administration departments to make timely corrections, have their illegal income confiscated, and may also be fined between RMB 50,000 and RMB 200,000 . Under extreme circumstances, the fine can reach up to RMB 500,000 (ECL, Art. 77).

The ECL further forbids e-commerce operators from setting unreasonable conditions for deposits required for online reservations, e.g., bike-sharing applications and hotel bookings. Where an e-commerce operator collects a deposit from a consumer according to an agreement, the procedure for the refund of deposit shall be clearly stated, and no unreasonable conditions shall be set. If a consumer applies for a deposit refund and meets these predefined conditions, the e-commerce operator shall promptly refund the deposit (ECL, Art. 21). Violators shall be ordered by the relevant authorities to make corrections within a timely manner, and if this is not the case, they may be subject to fines between RMB 50,000 and RMB 200,000. Under extreme circumstances, these fines can reach up to RMB 500,000 (ECL, Art. 78 (1)).

Where an e-commerce platform is an independently operated business, it shall be clearly marked on the platform as not to mislead consumers. E-commerce platforms shall bear legal civil liability for the sale of goods or provision of services marked as being their own, i.e., "self-operated" labels on e-commerce platforms, such as Tmall or Jingdong (ECL, Art. 37). The ECL prescribes an important division of liability between e-commerce platforms and on-platform business operators. The law states that where the e-commerce platform is aware, or should be aware, that goods or services sold or provided by an on-platform business operator do not comply with the requirements for personal or property safety protection, or otherwise infringe consumers' legitimate rights and interests, and fails to take any necessary measures, the e-commerce platform shall be jointly liable with the infringing on-platform business operator (ECL, Art. 38 (1)).

For goods or services related to consumers' health, such as medical products or treatments, e-commerce platforms bear "corresponding liability" towards effected consumers, together with the on-platform businesses, if they fail to review and verify the qualifications of on-platform businesses, or protect consumer safety (ECL, Art. 38 (2)). Violators shall be ordered by the market supervision and administration departments to make corrections in a timely manner, and may be subject to fines between RMB 50,000 and RMB 500,000. Under extreme circumstances, these fines could reach RMB 2,000,000 (ECL, Art. 83).

It appears that Article 38(2)'s terminology is vague and leaves the courts room to determine its interpretation: 1) Each party assumes liability based on its respective degree of fault; 2) Where the e-commerce platform has not acted in due 
diligence would it assume either a) joint and several liability with the on-platform operator, or b) just the losses not paid by the on-platform operator?

Similar to business operators, the ECL bans e-commerce platforms from deleting negative consumer reviews of goods and services. In fact, they must establish credit rating systems, and provide consumers with the opportunity to rate the goods or services offered on platform (ECL, Art. 39). Violators shall be ordered by the market supervision and administration departments to make corrections in a timely manner and fines can range between RMB 20,000 and RMB 100,000 . Under extreme circumstances, these fines could reach RMB 500,000 (ECL, Art. 81 (4)).

In addition, e-commerce platforms shall display search results of products and services to consumers through multiple methods such as based on their price, number of sales and ratings, while paid advertisements must be clearly labeled (ECL, Art. 40). Violators shall be punished in accordance with the provisions of the PRC Advertising Law (ECL, Art. 81).

\subsection{Intellectual Property Rights Protection and Unfair Competition}

The ECL underlines the protection of IP rights in the cyber domain, which can damage both legitimate business operators and consumers' rights and interests, and lists the prohibited activities that constitute unfair competition and undermine the credit rating systems (e.g., false advertising) (ECL, Art. 39, 41).

The ECL adopted the second draft's "notice-and-takedown" procedures that already existed in some form under PRC laws and regulations, ${ }^{4}$ most of which have already been adopted by a many of China's largest e-commerce platforms (A Game Changer? China Enacts First E-Commerce Law, 2018).

The ECL sets forth that e-commerce platforms must establish IP rights protection rules (ECL, Art. 41). This means that an IP rights' holder can file an infringement notice with an e-commerce platform, requesting "necessary measures", such as deletion, blocking or disconnection of links and termination of transactions and services of an infringing on-platform business operator. Such takedown notices must include prima facie evidence of the infringement (further implementation rules and judicial guidance on the level of prima facie evidence are required) (ECL, Art. 42), (A Game Changer? China Enacts First E-Commerce Law, 2018).

The e-commerce platform must then take appropriate measures (e.g., removing the postings or blocking links to allegedly infringing products, etc.) and must forward the notice to the on-platform business operator. Where the e-commerce platform does not promptly take such measures, it shall be jointly and severally liable for the additional damages incurred, together with the on-platform business operator. The IP rights' holder bears civil liabilities by law, if it causes any damage to a business operator by its wrongful notice and will indemnify any on-

${ }^{4}$ E.g., Zhonghua Renmin Gongheguo Qinquan Zeren Fa (中华人民共和国侵权责任法) the Tort Liability Law of the People's Republic of China (passed December 26, 2009, effective, July 1, 2010). 
line shops selling genuine products in good faith. If the IP rights' holder submits a wrongful notice with malice, its liability will be doubled (punitive damages) (ECL, Art. 42), (A Game Changer? China Enacts First E-Commerce Law, 2018).

The on-platform business operator may, in turn, file a notice of non infringement, which must also include prima facie evidence of non-infringement. The e-commerce platform must then forward this notice to the complainant and must advise the complainant to file a formal complaint with the authorities or bring a lawsuit before a people's court. If no such action follows within 15 days, the e-commerce platform must lift the measures it has adopted (ECL, Art. 43).

If the e-commerce platform is aware or should have been aware, of IP rights' infringements on their platform, but fails to take timely and necessary preliminary measures after a notice-and-takedown procedure, it shall be held jointly liable with the infringers for all damages caused(ECL, Art. 45). An e-commerce platform that has failed to fulfill these responsibilities and make corrections as ordered by the administrative departments for IP rights in a timely manner, could also be subject to fines ranging from RMB 50,000 to RMB 2 million (ECL, Art. 84).

To further strengthen IP rights' protection and violations easier to detect, all e-commerce operators (e.g., e-commerce platforms, on-platform business operators, and online sellers of self-established websites), must register with the State Administration for Industry and Commerce ("SAIC") to obtain a business license. There are some exceptions, such as sellers of home-grown agricultural products, handcrafters, sellers who engage in public services or deal in small sporadic transactions (ECL, Art. 10). This provision introduces a major change, since online stores, and the individuals operating them, were never required to apply for a business license (Eugene Low et al., 2017).

In addition, an e-commerce platform has a duty to remind on-platform business operators to obtain business licenses from administrative authorities and to require them to display their business license information on their web pages. Such requirements shall assist IP rights' owners in uncovering the identity of bad-faith IP rights' infringers and take action against them, such as closing down their online stores or disconnecting their links (Eugene Low et al., 2017), (ECL, Art. 15).

The ECL highlights fair-competition obligations for all e-commerce operators, especially those holding dominant market positions. Business operators that are superior in technology and scope, have control over relevant industries, or are key to other business operators' transactions, are prohibited from abusing their position to exclude or restrict competition. The ECL clearly states that business operators who violate its provisions by “... abusing their dominant market positions, or by acts violating IP rights or consumers' rights and interests ...”, shall be subject to sanctions in accordance with relevant laws (ECL, Art. 85).

Although the ECL touches upon antitrust issues, it does not add substantially to the existing legal framework laid out by the PRC Anti-Monopoly Law ("AML"). It seems to merely act as a reference to the AML and does not provide 
any sanctions for non-compliance. The only new content relative to the AML is the definition of factors that may help identify a dominant market position held by e-commerce players (A Game Changer? China Enacts First E-Commerce Law, 2018).

Furthermore, ban of bundling of products or services, for example, by default mechanisms discussed under Section C (Consumer Protection), should be mentioned again (ECL, Art. 19). Here, unlike Article 22, the ECL departs from the $\mathrm{AML}$, as it does not require the legal premise of the company at issue to be in a “dominant market position" (A Game Changer? China Enacts First E-Commerce Law, 2018). The ECL further underlines fair competition by prohibiting e-commerce platforms from exploiting service agreements and transaction rules, as well as technical methods imposing unreasonable restrictions, conditions upon any transactions or prices, or collect any unreasonable fees from on-platform business operators (ECL, Art. 35). This also applies to the sanctions faced by business operators imposing unreasonable conditions on consumers, as discussed earlier under the Consumer Protection Section (ECL, Art. 21, 78 (1)). Violators ordered by the market supervision and administration departments to make corrections, must do so within defined time limits and may be fined between RMB 50,000 and RMB 500,000. Under extreme circumstances, these fines can reach up to RMB 2,000,000 (ECL, Art. 82).

\subsection{Cross-Border E-Commerce and Tax}

E-commerce operators who conduct cross border e-commerce are subject to the same laws, regulations and other related rules on import and export supervision and administration (ECL, Art. 26). The decision to exclude the cross-border e-commerce activities from the ECL's second draft and subsequently adopted version, raises questions regarding the Chinese government's involvement in the development of a cross-border legal framework relevant for e-commerce. One of the areas that requires readdressing is the protection of personal and commercial data in cross-border e-commerce transactions, which is subject to the general Chinese data protection regime due to lack of specific legislation. This regime is now being reformed by a set of draft guidelines issued by the China National Information Security Standards Technical Committee (“TC260”). In addition, the Cyberspace Administration of China drafted the Administrative Measures for Cross-Border Transfer of Personal Information and Important Data, in April 2017, it has yet to be finalized (Zhong Lin and Galaad Delval, 2018).

Besides the business registration requirement with the SAIC, all e-commerce operators (including small-scale on-platform operators and operators active on social networks) are required to pay taxes on e-commerce revenues, but enjoy preferential tax treatment which before the adoption of the ECL, had largely been a regulatory and tax-free zone in China. This new policy arises from China's goal to promote the development of cross-border e-commerce by creating an efficient management system governing declaration, taxation, inspection and quarantine of imports and exports, and payment, etc. that will be identical for 
both offline and online industries. E-commerce business operators can get through relevant formalities with the authorities on the basis of electronic documents (e.g., electronic invoices). The national import and export administration department shall supervise these procedures and ensure their effective enforcement. The ECL requires e-commerce platforms to collect business license and identity information of small-scale web shops operating on their platform, and to submit it to the Chinese tax authorities (ECL, Art. 11, 14, 27-28, 71-72), (Eugene Low et al., 2017).

As a result, foreign retailers will not be permitted to directly participate in online sales in China and all online sales will be limited to licensed Chinese-owned entities. Foreign-owned operators of e-commerce platforms will also be excluded from operating in the Chinese market and the sales of foreign products will be forced to come into China through Chinese-owned or controlled platforms. The ECL's provisions on cross-border e-commerce focus on ensuring cross-border sales comply with Chinese laws and only approved products are imported into China after all taxes and duties on those products are paid. The ECL seeks to shut down online sales as a way to import illegal products into China as a method for evading China's taxes and import duties.

The plan is to funnel all cross-border e-commerce products through a limited number of e-commerce processing centers, all of which are controlled by the national government (e.g., The China Cross-Border E-Commerce Processing Pilot Area in Hangzhou). These processing centers will also be under the control of a single e-commerce platform (e.g., Alibaba Group) (Dickinson, 2017).

\subsection{E-Commerce Dispute Resolution}

The ECL underlines the protection of IP rights in the cyber domain, which can damage both legitimate business operators and consumers' rights and interests, and lists the prohibited activities that constitute unfair competition and undermine the credit rating systems (e.g., false advertising) (ECL, Art. 39, 41).

The ECL sets forth that disputes between parties to e-commerce activities may be resolved through negotiation, mediation (by consumer organizations, industry associations, or other legally founded mediation organizations), arbitration by an arbitral tribunal, or litigation before a people's court (ECL, Art. 60). In addition, the State encourages the establishment of online dispute-settlement mechanisms by e-commerce platforms to ensure the quality of goods and services that contribute to the development of e-commerce and to the protection of consumers' rights and interests (ECL, Art. 58).

The ECL adopts the second draft's broad approach towards dispute settlement mechanisms and pays great attention to this issue. It states that e-commerce platforms must establish convenient and effective complaint and reporting mechanisms, disclose complaint and reporting channels, and other original transaction information to the courts, arbitration authority and other mediation bodies. They shall also timely accept and handle any complaint and report. Otherwise, they shall be punished for faking, destroying, tampering with or refusing to 
hand-in such information. These provisions aim to address the challenges that consumers may encounter at the time they intend to exercise their consumer rights (ECL, Art. 59, 62), (Eugene Low et al., 2017).

\section{Arrangements for Online Trading Dispute Resolution}

\subsection{Consumer Redress Mechanisms}

The current Chinese consumer redress system consists of both the court-based and the Alternative Dispute Resolution (ADR) (non-court-based) approaches. The court-based approach acts as a last resort, and it is rarely used by consumers.

The reasons why the court-based approach is not considered a practical solution are well-known: it is a costly, complicated and lengthy procedure. Chinese arbitration systems were formed and developed for resolving Business to Business (B2B) disputes, rather than occurring in Business to Consumer (B2C) e-commerce. The vague nature of the division of responsibilities between individual administrative departments discourages consumers, as does the behavior of bureaucratic officials within the administration. The effectiveness of the B2B-based ADR system mainly relies on the parties' autonomy and it is difficult to refer a case to the consumer redress mechanism, since it is based on sellers' cooperation (Yu and Shen, 2015).

According to the 2013 PRC Consumer Protection Law (Law of the People's Republic of China on Protection of Consumer Rights and Interests, 2013), there are five routes for consumer redress in disputes with business operators over consumer rights and interests. Consumers may settle the disputes by choosing one of the following: 1) to consult and conciliate with business operators; 2) to file a request to consumer associations (or other ADR mechanisms) for mediation; 3) to appeal to relevant administrative departments; 4) to apply to arbitral organs for arbitration according to the arbitral agreements with business operators; or 5) to institute legal proceedings in the people's court (PRC Consumer Protection Law, Art. 39). Inaddition, consumers whose rights and interests have been infringed upon when purchasing goods or using services, may demand compensation from the sellers or suppliers of the goods or services concerned (PRC Consumer Protection Law, Art. 40).

From among these five types of consumer redress institutions recognized by Chinese law, the China Consumers Association ("CCA") is the sole entity that is capable of resolving some consumer disputes. The CCA is a special, large, quasi-government consumer organization in China that has developed 3279 branches around the country since its founding in 1984 by the State Council (Minglei Gao, 2018). In 2017, the CCA processed 726,840 consumer complaints, resolving 552,398 cases, which is a respectable $76 \%$ resolution rate, saving consumers economic losses of RMB 516.39 million. The CCA accepted 69,397 sales and service complaints in 2017, a year-on-year increase of $78.25 \%$. Among them, online shopping complaints were particularly prominent, accounting for $59.31 \%$ of 
sales service complaints (State Administration of Industry and Commerce of the PRC, 2018).

However, these five routes of consumer redress, while certainly an important tool for consumer protection, still have room for improvement as far as efficiency is concerned, especially for the large number of middle-class Chinese Internet consumers. Business operators often disregard consumers' rights, and the consumer redress system provided by judicial tribunals is weak, which is a constant source of frustration for Chinese consumers. Public enforcement cannot effectively deal with major events, not to mention constant minor online transactions. In general, Chinese consumers conceive private institutions to be more reliable than public ones, and which can assist them in achieving compensation if something goes wrong ( $Y u$ and Shen, 2015).

Another consumer redress mechanism under Chinese legislation is offered by e-commerce platforms. E-commerce platforms are required to establish self disciplinary mechanisms for resolving disputes and protecting consumers' rights. A consumer who is involved in such a dispute or their legitimate rights and interests have been infringed upon, can seek mediation through the platform. If the consumer wishes to protect their rights through other channels, the e-commerce platform shall provide the real website registration information of the relevant business operator, and actively assist the consumer in protecting their legitimate rights and interests (Measures on the Administartion of Online Transactions, Art. 28, 2014).

As of March 29, 2018, the total number of cases resolved by Taobao ${ }^{5}$ and by Alipay's ${ }^{6}$ Online Dispute Resolution (ODR) procedures reached to 2,632,553 (Lizhi Liu and Barry R. Weingast, 2018). Taobao resolves two types of disputes: 1) disputes between trading partners (e.g., a seller and a buyer; or two competitors), which often involve contract violations (e.g., complaints about items received that fail to match store descriptions); and 2) disputes between trading partners and Taobao, in which the seller believes that Taobao has unfairly penalized it for violating certain rules. When a dispute arises, the party initiating the procedure may choose from two routes: 1) asking a designated Taobao employee to decide; or 2) using a jury-like panel of public assessors to arbitrate (Lizhi Liu and Barry R. Weingast, 2018).

In addition, Taobao has several means of enforcing decisions such as freezing the payment in dispute, taking money from the store's deposit (for sellers only), lowering the rating of involved users, or denying the losing party's privileges to use the platform. Alipay is an important part of Taobao's private legal system and provides a means of enforcing decisions and a means of enforcing users to operate within the system, since when dispute over a transaction arises, it can freeze or deduct the payment in escrow, forcing conflicting parties to choose between losing the money or engaging in, and complying with, Taobao's dispute resolution system (Lizhi Liu and Barry R. Weingast, 2018).

${ }^{5}$ Chinese online shopping website owned by Alibaba Group.

${ }^{6}$ Alibaba's online payment and escrow services provider. 
This new consumer-oriented-mechanism can improve the way consumer disputes are resolved, lower costs for consumers looking for remedy, increase their chances to receive compensation and improve the protection of consumer rights.

\subsection{Internet Courts}

On June 26, 2017, the 36th session of the Central Committee for Deepening Reform of the Communist Party of China ("CPC") reviewed and approved the "Plan for the Establishment of the Internet Court in Hangzhou", which became the world's first Internet court and an important advancement in the development of China's e-commerce market (TMTPost, 2017), (Tong, 2017).

Following the establishment of the Hangzhou Internet Court on August 18, 2017, two other Internet courts were established in Beijing and Guangzhou (on September 9, 2018 and September 28, 2018, respectively). On September 3, 2018, China's Supreme People's Court published the "Provisions of the Supreme People's Court on Several Issues Concerning the Hearing of Cases by Internet courts" (the "SPC Provisions"), clarifying the types of cases within the jurisdiction of these courts and regulating certain procedural issues relevant to Internet courts.

The SPC Provisions clarify the "online-ness" of the internet courts: An internet court shall conduct cases online, and the acceptance, service, mediation, evidence exchange, pre-trial preparation, court trial, judgment pronouncement and other litigation links concerning a case shall also be completed online. According to the application of a party, or as needed for the trial of a case, an internet court may decide to complete part of the litigation process offline (SPC Provisions, Art. 1).

Furthermore, the internet courts have the jurisdiction to handle a broad range of cases (SPC Provisions, Art. 2):

- Contract disputes involving online shopping;

- Financial and small loan contracts;

- "Internet copyright" and neighboring rights ownership and infringement;

- Domain name disputes;

- Infringement on personal or property rights via the Internet;

- Product liability claims for goods purchased online;

- Internet public interest litigation brought by prosecutors;

- Administrative disputes with relevant authorities, such as Internet information service; management, internet commodity trading and the management of relevant services;

- Other civil and administrative internet cases designated by a higher people's court.

Internet courts are aimed to specifically accept legal cases related to the Internet and e-commerce, and they are better equipped to hear and handle such cases. Internet courts are expected to be more approachable, efficient and cost-effective than traditional courts as their decisions shall be based on the recent SPC Provi- 
sions and on several innovative facilities, e.g., the judicial blockchain platform and asynchronous trial, which allows parties to upload documents, arguments and responses (within a defined period), which will shorten the average trial period (TMTPost, 2017), (Yan Jie, 2017), (Tian Lu, 2018).

Currently, all three Internet courts are trial courts within the jurisdiction of their own cities, and most appeals are heard by the intermediate courts in their respective jurisdictions. However, online copyright-ownership and infringement disputes and domain-name disputes tried by Guangzhou and Beijing Internet courts shall be appealed to the Intellectual Property Courts in their respective cities (SPC Provisions, Art. 4).

By taking these steps, the Chinese government builds up its legal scrutiny over the Internet and is adapting to the growing trend of Internet development. According to the "People's Court Daily", the first internet court was launched in Hangzhou for two main reasons: first, it is home to vibrant Internet industry and home to a large number of well-known Internet-related companies, including the e-commerce giant, Alibaba Group. This could result in a large number of Internet-related disputes, and therefore, such judicial institutions are needed there. The second reason is that Hangzhou already has a solid base for the trial and litigation of Internet-related disputes (TMTPost, 2017).

On August 13, 2015, the Zhejiang E-Commerce Court declared its intent to shift the entire process of litigation from court rooms to the online environment. This announcement was made after a successful pilot program of the Zhejiang High Court, in which three Hangzhou trial courts and the Intermediate Court of Hangzhou handled online cases in addition to traditional court sessions. According to the Zhejiang E-Commerce Court's spokesperson, the establishment of the Hangzhou Internet Court "could improve the efficiency of case handling, because both parties to an e-commerce case are often not located in the same city". The statement continues with "it is a new path to solve the rising number of e-commerce disputes, since most of them have clear facts and solid evidence" (TMTPost, 2017), (E-Commerce Online Court of Zhejiang Court).

Online shoppers have saved millions of RMB in legal costs since they are able to manage the entire litigation process online, including filing legal documents (SPC Provisions, Art. 7), submitting evidence (SPC Provisions, Art. 9) and even attending court hearings through online video technology (SPC Provisions, Art. 12). In fact, a lawsuit can be filed online in just five minutes (The Litigation Platform of Hangzhou Internet Court). In these Provisions, the Supreme People's Court confirms that the Internet courts may consider electronic evidence provided by the parties that can be authenticated by electronic signatures, time stamps and hash value, blockchain and other tamper-proof verification methods (SPC Provisions, Art. 11). In fact, before the SPC Provisions were announced, the Internet court in Hangzhou, for the first time in the country's history, admitted evidence that was authenticated by blockchain technology in an online copyright infringement case (Sara Xia, 2018).

The number of lawsuits linked with online shopping has sharply increased in 
recent years along with China's rapid e-commerce growth. In Hangzhou alone, the number of e-commerce cases has grown from 600 in 2013 to over 10,000 in 2016 (Tong, 2017). By the end of August 2018, the Hangzhou Internet Court has handled 12,103 Internet cases, of which 10,646 have been decided. An online trial process only takes 28 minutes on average and the average duration of a trial period is 41 days, about $60 \%$ less of the time in traditional courts (Qiao Wenxin, 2018).

Most internet-related disputes stem from purchases on popular Chinese online marketplaces, such as Alibaba's Taobao. Consumers often complain about product quality and return policies (Tong, 2017).

\section{Conclusion}

The Internet, as a unique medium based on innovation and constantly changing technology, and as infrastructure for e-commerce around the world, raises serious questions regarding the validity of traditional concepts of law and the suitable means of its regulation. Traditional laws are based on territorial boundaries and physical concepts, yet the sphere of the Internet is a non-physical medium constructed of a single global network whose boundaries are not territorial. Consequently, there is difficulty in applying territorial-based laws to the Internet and the e-commerce activities it hosts (Azam, 2010).

The Internet introduced far-reaching changes that influence all aspects of consumer activity: the nature of the products traded, marketing channels and methods, pricing, sales, consumer characteristics and shopping campaigns, the "intermediators" involved in transactions, etc. In doing so, it has created completely new markets through which consumer transactions are processed. These new digital markets differ in structure and characteristics from the classic market, which means consumer transactions carried out via the Internet cannot necessarily be regulated by laws made for the classic market (Jabareen, 2015).

China's new E-Commerce Law analyzed in this article serves as the basis for Chinese online trading legislation. This article examined the grounds for adoption of the E-Commerce Law based on a solid theoretical foundation and proper policy as presented in the ECL and its drafts. The ECL addresses all issues stemming from e-commerce (e.g., contracts, consumer protection and privacy, fair competition, intellectual property rights, tax, dispute resolution, fines and penalties etc.), instead of dealing with fragments of laws regulating e-commerce activities as was the case before its adoption.

The findings in this article indicate that Chinese legislation and government policy concerning the Internet are among the most advanced in the world and include detailed and specific provisions defining the relations between e-commerce platforms, business operators and consumers in online transactions. An example of this can be seen in the Establishment of the First Professional Internet Court in Hangzhou, Zhejiang to address and solve internet-related disputes. China has even continued to expand its internet courts from one city to three, (including Beijing and Guangzhou), thus supporting the State's desire to promote online 
retail transactions and to increase consumer confidence in China's online economy (ECL, Art. 58).

China's internet courts provide the opportunity to modernize and reshape the dispute-resolution process to provide greater access and ease for those who feel excluded from the public justice system. It also introduces an effective route to deal with the growing number of internet-related disputes across the country. Nevertheless, it is still difficult to assess the effectiveness of judgements rendered by these courts and their enforcement. It will be interesting to see how fast these Internet courts develop within China in the future and in the rest of the world.

On the one hand, it appears that the PRC ECL aims to introduce more structure and credibility to e-commerce transactions and set forth a series of customer-rights' protection measures to improve the online shopping experience. However, some of the ECL provisions are not actually a significant departure from current PRC laws and there are doubts as to how it will be enforced on a day-to-day basis. Nonetheless, it is clear that after the ECL's adoption, e-commerce platforms in China are expected to do more to protect the IP rights of both owners and consumers. Consequently, it is the most appropriate law for internet-related disputes and rulings in China's Internet courts, along with the new SPC Provisions and authority awarded to these courts.

On the other hand, the ECL raises many questions that will be the subject of further debate and lobbying as the rules for its implementation have yet to be drafted. The broad wording in some areas is not unusual as it allows the Chinese authorities flexibility in applying the ECL, for example: 1) the nature of the prima facie evidence needed to be included in the "notice and take-down" procedures and whether this increases the burden on IP rights' owners; 2) The ECL provides for penalties in the case of incorrect or malicious notifications, but does not actually specify who will bear the liability; 3) Liability of online sellers and service providers that are "aware, or should have been aware", that relevant goods and services on their platform infringe consumers' rights and interests, or others' IP rights; 4) Joint liability of e-commerce platforms with the online seller, where the e-commerce platform operator is "aware, or should have been aware", that an online seller violated another's IP rights and fails to take necessary measures to prevent such violations.

E-commerce and online retail require the legal world to be ready and adapt rapidly in response to technological developments of the Internet and its services. As online retail is just one aspect of an easier and accessible daily activity for all people, legal recourse should be no different. Parties seeking judicial remedy regarding Internet and online retail cases shall be able to access decisions in an easy and timely manner, whilst performing all stages of the process online, according to updated legislature that credibly reflects the ever-changing legal aspects in the Internet era.

I would like to finish this article with the words of Albert Einstein:

"The world as we have created it is a process of our thinking. 
It cannot be changed without changing our thinking."

\section{Conflicts of Interest}

The author declares no conflicts of interest regarding the publication of this paper.

\section{References}

(1999). Contract Law of the People's Republic of China.

(2009). The Tort Liability Law of the People's Republic of China.

(2010). Administrative Measures for the Payment Services Provided by Non-Financial Institutions.

(2013). Law of the People's Republic of China on Protection of Consumer Rights and Interests.

(2014). Measures on the Administration of Online Transactions.

(2016). Cybersecurity Law of the People's Republic of China.

(2016). Draft E-Commerce Law of the People's Republic of China (Chapter 4, Section 1). http://www.ictplus.gr/files/PDF\%20FILES/Draft E Commerce Law.pdf

(2017). Miriam Webster Unabridged Online Dictionary. Definition of E-Commerce. https://www.merriam-webster.com/dictionary/e-commerce

(2017). Tencent Holdings Plans to Expand WeChat Pay beyond China. TechPapa. http://mp.weixin.qq.com/s/iyGk0m0d9Bb72bD23MmrfA

(2018). A Game Changer? China Enacts First E-Commerce Law. http://www.conventuslaw.com/report/a-game-changer-china-enacts-first-e-commerce$\underline{\text { law }}$

(2018). E-Commerce Law of the People's Republic of China.

(2018). New China Data Privacy Standard Looks More Far-Reaching than GDPR. CSIS. https://www.csis.org/analysis/new-china-data-privacy-standard-looks-more-far-reachi ng-gdpr

(2018). Provisions of the Supreme People's Court on Several Issues Concerning the Hearing of Cases by Internet Courts.

(n.d.). E-Commerce Online Court of Zhejiang Court. http://www.yuncourt.com

(n.d.). The Litigation Platform of Hangzhou Internet Court. https://netcourt.yuncourt.com/portal/main/domain/index.htm?lang=En

Azam, R. (2010). The Electronic Commerce Bill and the Integrative Adaptation Model of E-Commerce Regulation and Taxation. Law \& Business (IDC Law Review), 13, 214-215. https://doi.org/10.2139/ssrn.1735429

Azam, R. (2013). The International Taxation of Electronic Commerce. Srigim Li On: Nevo Publishing.

Canadian Advisory Committee on Electronic Commerce (1998). Canada, Electronic Commerce and Canada's Tax Administration: A Report to the Minister of National Revenue from the Minister's Advisory Committee on Electronic Commerce $\$ 1.2$ (April). Ottawa: Revenue Canada.

China Daily (2017). Beijing Tops Study of Cashless Living in Cities. http://www.chinadaily.com.cn/china/2017-08/01/content 30313675.htm

Dickinson, S. (2017). China E-Commerce: Resistance Is Futile. China Law Blog. 
https://www.chinalawblog.com/2017/11/china-e-commerce-resistance-is-futile.html

Eshopworld (2019). Insights into the Growth of China's E-Commerce with Payment Methods, Target Audiences, Marketing, Social Media, Economy and Logistics All Profiled. https://www.eshopworld.com/blog/china-ecommerce-insights

Eugene Low et al. (2017). China Issues Its Second Draft E-Commerce Law. Hogan Lovells.

https://www.hoganlovells.com/ /media/hogan-lovells/pdf/2017/20171221-china issues its second draft e-commerce law.pdf?la=en

https://www.limegreenipnews.com/2017/12/china-issues-its-second-draft-e-commerce -law

Gao, M. (2018). Restructuring Economic Development in China: A Better Consumer Protection Regime in a Consumption-Driven Economy. Cornell Policy Review. http://www.cornellpolicyreview.com/consumer-protection-china/?pdf=4521\#post-4521 -footnote-13

Girasa, R. J. (2002). Cyberlaw: National and International Perspectives. Upper Saddle River, NJ: Prentice Hall.

Graziani, T. (2018). 2018 Double 11 Data: Alibaba, WeChat, Pingduoduo and More. WalktheChat.

https://walkthechat.com/2017-singles-day-sales-data-39-yoy-growth-tmall

HFG Law \& Intellectual Property (2017). China Publishes Draft E-Commerce Law. Lexology. http://www.lexology.com/library/detail.aspx?g=629d16f4-93f9-4f36-98f1-5ea7315d8aaa

Ipsos (2017). 2017 Mobile Payment Usage in China Report.

https://www.ipsos.com/sites/default/files/ct/publication/documents/2017-08/Mobile p ayments in China-2017.pdf

Israeli Chamber of Commerce in Beijing (2016). Guidelines for the Israeli Investor in the Chinese Market.

http://economy.gov.il/Publications/Publications/Pages/ChinaEcommerce.aspx

Jabareen, A. (2015). The Law and Business to Consumer Electronic Commerce (Part II). Srigim Li On: Nevo Publishing.

Kharpal, A. (2018). Alibaba Sets New Singles Day Record with More than \$30.8 Billion in Sales in 24 Hours. CNBC.

https://www.cnbc.com/2018/11/11/alibaba-singles-day-2018-record-sales-on-largest-sh opping-event-day.html

Li, J. (2003). International Taxation in the Age of Electronic Commerce: A Comparative Study.

Li, X. (2018). China's 2nd Internet Court Opens in Beijing. Xinhuanet. http://www.xinhuanet.com/english/2018-09/09/c 137456299.htm

Liang, Y. (2018). China Focus: China Has 802 Million Internet Users. Xinhuanet. http://www.xinhuanet.com/english/2018-08/21/c 137405424.htm

Liu, L., \& Weingast, B. R. (2018). Taobao, Federalism, and the Emergence of Law, Chinese Style, 1581. Minnesota Law Review, 102, 1563-1590.

Lu, T. (2018). Do China's Internet Courts Work Entirely Online? The IPKat. http://ipkitten.blogspot.com/2018/12/do-chinas-internet-courts-work-entirely.html http://ipkitten.blogspot.com/2018/12/in-math-we-trust-china-cyberspace.html

Luo, K. (2016). E-Commerce Laws and Practices in China. Arizona Journal of International and Comparative Law, 33, 220-228. 
National Bureau of Statistics of China (2019). National Economic Performance Maintained within an Appropriate Range in 2018 with Main Development Goals Achieved. http://www.stats.gov.cn/english/PressRelease/201901/t20190121 1645832.html

O’Brien, M. (2017). Chinese Ecommerce Market Pegged at \$1.7 Trillion by 2020. Multi Chanel Merchant.

http://multichannelmerchant.com/news/chinese-ecommerce-market-pegged-1-7-trillio n-2020/\#

Orendorff, A. (2018). Global E-Commerce Marketplaces: The Complete List by Region and Sales. Shopify.

https://www.shopify.com/enterprise/global-ecommerce-marketplace\#asia-pacific

Qiao, W. (2018). The Person in Charge of the Reform Office of the Supreme People's Court Responded to the Judicial Interpretation of the Trial of the Internet Courts. People's Court Daily. https://www.chinacourt.org/article/detail/2018/09/id/3489190.shtml

Shackleton, T. (2016). Online vs. Offline Retail: Pros, Cons \& an Omni-Channel Future. Statement.

https://www.statementagency.com/blog/2016/08/online-vs-offline-retail-pros-cons-anomni-channel-future

Smith, A. (1776). The Wealth of Nations (Vol. 1). London: Cannan Edition.

State Administration of Industry and Commerce of the PRC (2018). China Consumers Association Announced Nation-Wide Consumers' Reception of Complaints in 2017. http://www.gov.cn/xinwen/2018-01/31/content 5262466.htm

Statista (2017). Global Retail E-Commerce Market Size 2014-2021 (in Billion U.S. Dollars). https://www.statista.com/statistics/379046/worldwide-retail-e-commerce-sales

Statista (n.d.). Annual Retail E-Commerce Sales Growth Worldwide from 2014 to 2021. https://www.statista.com/statistics/288487/forecast-of-global-b2c-e-commerce-growt

TechPapa (2017). China's Fin Tech Industry Shows Where the World Is Heading. http://mp.weixin.qq.com/s/NRohCBh-iS6aArGksDM2hQ

That's Shanghai (2017). Alibaba Crushes Singles Day Records with RMB 168.2 Billion in Sales. https://mp.weixin.qq.com/s/Cq819MWSn1WTyGs6j8mqVg

TMTPost (2017). China to Launch the First Internet Court in Hangzhou. TMTPost. http://www.tmtpost.com/2655910.html

Tong, F. (2017). China Creates an Online Court to Handle E-Commerce Disputes. DigitalCommerce360.com.

https://www.digitalcommerce360.com/2017/07/06/china-creates-online-court-e-comm erce-disputes

Xia, S. (2018). China's Internet Courts Are Spreading; Online Dispute Resolution Is Working. China Law Blog.

https://www.chinalawblog.com/2018/12/chinas-internet-courts-are-spreading-online-d ispute-resolution-is-working.html

Yan, J. (2017). China Launches Court for Internet Cases in Hangzhou. SIXTHTONE. http://www.sixthtone.com/news/1000408/china-launches-court-for-internet-cases-in-h angzhou

Yu, Y., \& Shen, M. (2015). Consumer Protection as the "Open Sesame" That Allows Alibaba to Crush the Forty Thieves (Gaining Market Power by Protecting Consumers: A Private Company Blows China's Banks Away). Journal of Antitrust Enforcement. https://doi.org/10.2139/ssrn.2572941 
Zhong, L., \& Galaad, D. (2018). China: Out For Comments, the Second Draft of the E-Commerce Law Brings the Legislation Closer to Adoption. Mondaq.

http://www.mondaq.com/china/x/668716/Contract+Law/Out+For+Comments+The+S econd + Draft + Of + The + ECommerce + Law + Brings + The+Legislation+Closer+To+Adop $\underline{\text { tion }}$ 